\title{
Situated Analysis of Team Handball Players' Decisions: An Exploratory Study
}

\author{
Benoît Lenzen \\ University of Geneva \\ Catherine Theunissen and Marc Cloes \\ University of Liège
}

\begin{abstract}
This exploratory study aimed to investigate elements involved in decision making in team handball live situations and to provide coaches and educators with teaching recommendations. The study was positioned within the framework of the situated action paradigm of which two aspects were of particular interest for this project: (a) the relationship between planning and action, and (b) the perception-action coordination. We used qualitative methods that linked (a) video observation of six female elite players' actions during two championship matches and (b) self-confrontation interviews. Players' verbalizations reflected that their decision making included the following: (a) perception (visual, auditory, tactile, proprioceptive), (b) knowledge (concepts, teammates and opponents' characteristics, experience), (c) expectations (opponents and teammates' intentions), and (d) contextual elements (score, power play, players on the field, match difficulty). Findings were discussed in terms of teaching implications.
\end{abstract}

Keywords: perception, knowledge, expectations, context, didactics

Recently, there has been renewed interest in the teaching of team sports (Gréhaigne, Richard, \& Griffin, 2005). During the last two decades, the debate regarding the teaching of team sports has essentially been a matter of technical versus tactical approaches. The former, which is a behavioral approach, consists of mastering a series of technical skills to be exploited later in game situations (Gréhaigne et al., 2005). The tactical approach, which is a constructivist and cognitive approach, emphasizes game appreciation and tactical awareness as a basis for making game play decisions, with learners discovering when and why skills are needed in a game context (Bunker \& Thorpe, 1982; Gréhaigne et al., 2005).

Numerous research studies have been conducted on the technical/tactical approaches to games teaching. Some have confirmed the tactical approach's superior influence on the development of decision making (Turner, 1996) and on the

Lenzen is with the Institute of Movement Sciences and Sport Medicine, University of Geneva, Geneva, Switzerland, and Theunissen and Cloes are with the Department of Movement Sciences, University of Liège, Liège, Belgium. 
acquisition of declarative knowledge (Allison \& Thorpe, 1997; Griffin, Oslin, \& Mitchell, 1995; Mitchell, Griffin, \& Oslin, 1995; Turner, 1996). Other studies_-or parts of the previous studies - have failed to discriminate between the benefits of both approaches to the development of decision making (Mitchell et al., 1995 ; Turner \& Martinek, 1992), the acquisition of declarative and procedural knowledge (Lawton, 1989 ; Turner \& Martinek, 1992), and the development of motor skills (Griffin et al., 1995; Lawton, 1989; Mitchell et al., 1995; Turner, 1996; Turner \& Martinek, 1992).

The lack of sufficient time for experimentation and the use of inappropriate tools have been put forward to explain such inconsistencies (Gréhaigne et al., 2005). The development of appropriate tools for assessing - and then improving-learners' performance needs to be supported by more time in the field (quantitative aspect) and a better understanding of decision making in complex sport situations (qualitative aspect). Teachers have to understand what it really means to make successful decisions in game situations before being able to develop effective teaching strategies to support that outcome. That is, we need lengthy field data on decision making in team sports to provide physical educators and student teachers with useful teaching recommendations on the development of students' decision making, and that is the purpose of this study.

Research on decision making in sport comes within the framework of different-sometimes contradictory-paradigms: (a) information-processing system (e.g., Newell \& Simon, 1972; Ripoll, Kerlirzin, Stein, \& Reine, 1995); (b) decision field theory (e.g., Busemeyer \& Townsend, 1993; Raab \& Johnson, 2004); and (c) situated action (e.g., Sève, Saury, Ria, \& Durand, 2003; Suchman, 1987).

The description of the three paradigms and their related methods would be too tedious and inappropriate here. Therefore, we will limit ourselves to addressing the third one, insofar as the practical intent of our study, coupled with our qualitative approach to the research questions, have driven us to prioritize the theory of situated action (Suchman, 1987). According to this theory, the aim of research "is not to produce formal models of knowledge and action, but to explore the relation of knowledge and action to the particular circumstances in which knowing and acting invariably occur" (pp. 178-179). Two aspects of this theory were of particular interest for our project: (a) the relationship between planning and action and (b) the perception-action coordination.

First, a person often has to change the plans of action that have been mapped out in his or her mind, depending on what is happening in a specific situation. Suchman (1987) considers that people construct their plan as they proceed, creating their next move based on what just happened. In this view, plans are resources for action rather than determinants of action. In Suchman's (1987, p. 52) example, one may plan a descent through a series of rapids ("I'll get as far over to the left as possible, try to make it between those two rocks, and then back-ferry hard to the right to make it around the next bunch"), but one does not steer the canoe by merely executing that plan. This conception fits well with Gréhaigne and his colleagues' distinction between strategy and tactics in team sports (Gréhaigne, Godbout, \& Bouthier, 1999). A strategy refers to "all plans, principles of play, or action guidelines decided upon before a match in order to organize the activity of the team and the players during the game." A tactic involves "all orientation operations voluntarily executed during the game by the players in order to adapt, to the 
immediate requirements of an ever-changing opposition, their spontaneous actions, or those organized through the predetermined strategy" (Gréhaigne et al., 1999, p. 166). The player has some freedom within the framework of preestablished plans and uses it as evidenced by what happens in game play (Lenzen, Brouwers, Dejardin, Lachi, \& Cloes, 2004; Mouchet, 2005). In the current study, we make such a distinction between strategy and tactics when discussing results of our investigation.

Second, a basic assumption of the information-processing system approach is that perception and reasoning are possible without action (Newell \& Simon, 1972). In contrast, researchers who favor a situated action paradigm (Clancey, 1993) consider that all action is embodied because perception and action occur simultaneously: "To be perceiving the world is to be acting in it - not in a linear input-output relation (act-observe-change) — but dialectically, so that what I am perceiving and how I am moving co-determine each other.' (Clancey, 1993, p. 95). Hence, a decision cannot be separated from action, and it is recommended that perception and action should be coupled for the analysis of experts' performance (Gréhaigne et al., 2005; Williams \& Grant, 1999). The description of our methodology will make clear how we have taken this recommendation into account.

A few authors have analyzed the activity of elite players during matches, within the situated action paradigm. On one hand, Sève et al. (2003) have more specifically addressed knowledge construction during top-level table tennis competitive interaction. They collected videotape data supplemented with verbalization data from interviews in which elite players viewed the videotapes and were asked to describe and comment upon their activity. The analysis focused on (a) the elements the players took into account for deciding what action to take, (b) the centers of interest underlying their activity, and (c) the knowledge they activated and constructed. The results showed that in the early moments of the match, players were looking for what strokes bothered their opponent (discovery period). Then, players were constructing and validating new knowledge about the opponent by testing hypotheses (inquiry phase). At the same time, they were trying to reproduce actions identified as effective in the inquiry phase, to score points (executory phase).

More recently, Sève and Ria (2006) have assessed the impact of the new scoring system on expert table tennis players' activity during competitive interaction. Matches under the old scoring system (game won by the player first scoring 21 points; after each 5 points have been scored, the server becomes receiver) and the new scoring system (game won by the player first scoring 11 points; after each 2 points have been scored, the server becomes receiver) were analyzed through the previously described method (Sève et al., 2003). Comparison of players' activity showed that (a) players adopted similar inquiry and executory strategies whatever the scoring system, but (b) temporal organization of the inquiry and executory phases was different according to the scoring system. Under the new scoring system, the discovery and inquiry phases ended earlier, and the ratio inquiry phase/executory phase was lower. These findings underline the influence of context on decision making in sport and should encourage researchers to collect field data in various contexts. 
On the other hand, some studies investigated decision making in team sports (Mouchet, 2005; Mouchet \& Bouthier, 2006). These researchers addressed more particularly rugby players' subjectivity when making decisions in matches, through the use of a hybrid method combining video and various forms of interview. The more significant results of 6 case studies including a total of 11 elite players ( 5 forward and 6 full backs) were presented by Mouchet and Bouthier (2006): (a) players shared common representations about a few conditions of efficacy (vision of play, standing play, roles and distribution of players on the field, keeping the ball, technical skills, physical conditions) and cues (tactical positioning of players on the field after static play); (b) players' representations about most conditions of efficacy (especially regarding playing in movement) and cues were heterogeneous; (c) background elements (e.g., beliefs about teammates and opponents, previous experience, habits and preferences) exerted a strong influence on players' decision making; and (d) players had developed attentional skills allowing them to perceive subjective cues in their local environment. These findings throw new light on the previously mentioned distinction between tactics and strategy by taking into account players' subjectivity in real-world settings. However, more data are needed to better understand the respective influences of collective plans and individual rationalities on players' decision making in team sports, with the aim of developing more effective teaching strategies and didactic contents.

In this exploratory study, we intend to answer the following questions: (a) What do elite team handball players take into account when making successful decisions in real game situations? (b) How can we make the connection between these findings and teaching strategies to support that purpose?

\section{Methods}

\section{Participants}

Six elite female team handball players consented to participate in this study (for more information on team handball, see http://www.ihf.info). They were members of a leading team in the first Belgian league for 3 to 8 years (six times national champion, six-time winners of the National Cup, and competed regularly in the European Cup). In Europe, the sport organization is based on clubs that are independent of the school system. Clubs compete in championships organized by sport federations, involving 10 to 16 teams by division and planned between September and April with one match per weekend per team.

Their characteristics are listed on Table 1.

\section{Games}

We focused on two championship matches. Match 1 (January) was against the team that had won the national championship the previous season. Match 2 (March) was against a team that was firmly entrenched at the bottom of the standings for several years. By choosing these two contrasting matches, we expected to 


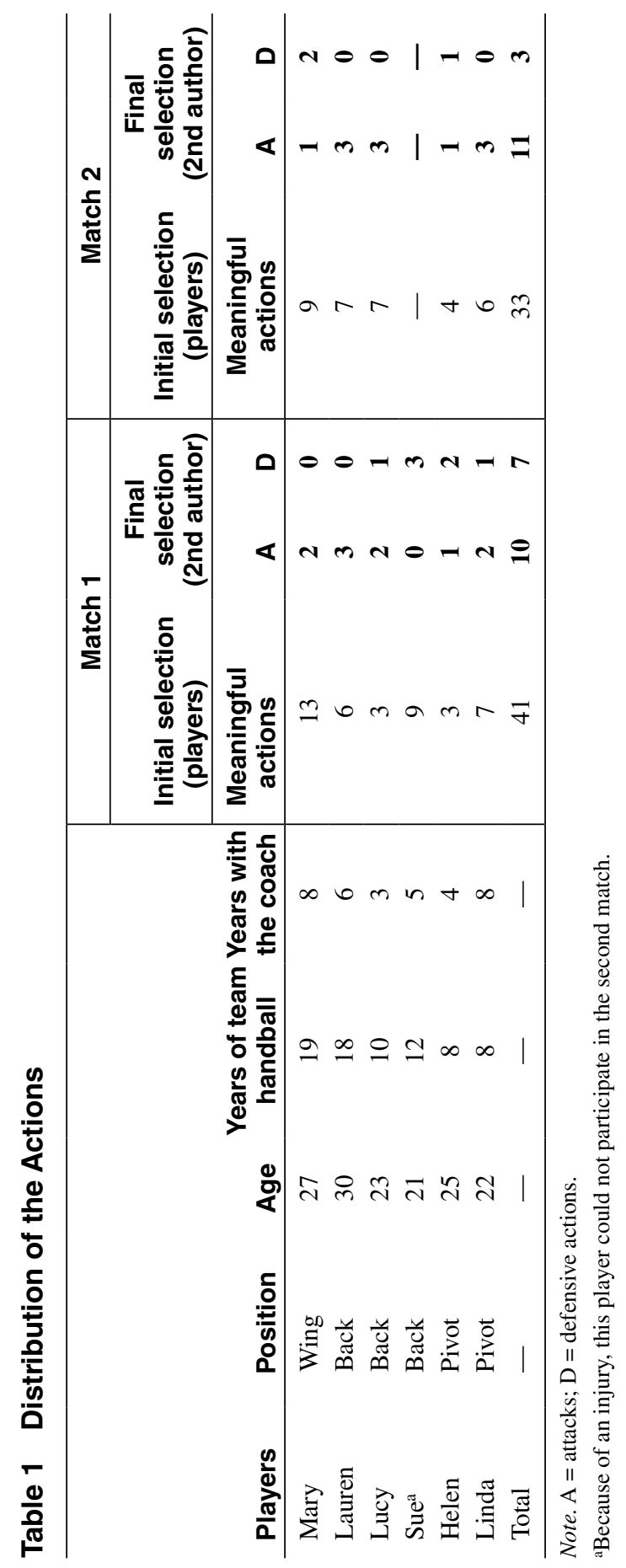


address the influence of context on decision making. Surprisingly, both matches were won easily (35-9 and 34-12).

\section{Data Collection}

For each match, we collected data in the following three steps.

Videotape/Audiotape. Both 30-min halves were videotaped and the coach's instructions were audiotaped with a wireless microphone. One of the researchers audiotaped the coach's speech during the 10-min half-time.

Action Selection. The day after the match, the players collectively watched the video and individually listed on paper the successful actions for which they thought that they could remember the elements involved in their own decision making. According to several authors (Faingold, 2001; Mouchet, 2005), the choice of the actions by the participants themselves is preferable to the one made by the researcher insofar as it reflects the importance that participants attach to their actions. That is the reason why we asked the players to operate this initial selection, which has resulted in 41 meaningful actions for Match 1 and 33 for Match 2 (Table 1). Then, as a recognized specialist in team handball, the second author viewed these sequences and selected up to three actions per match for each participant, so that following interviews relying on players' actions last about $30 \mathrm{~min}$. She chose the actions that were (a) most representative of team handball actions and (b) visible on the video. This final selection has resulted in 17 sequences for Match 1 and 14 sequences for Match 2. These final sequences concerned 21 attacks, such as attack with interchanging positions, counterattack, crossing of players, cutting around the defense, and penetrating into the defense, and 10 defensive actions, such as falling back, stealing the ball, covering the angle, and blocking the movement of the opponent (Table 1). Data obtained at this stage are not strictly results regarding our project. They just have served as support for the third step of the data collection, described in the next paragraphs.

Self-Confrontation Interview. During the following week, we individually presented the participants with their respective sequences and subjected them to a "self-confrontation interview" (Theureau \& Jeffroy, 1994). This consisted of asking them, while viewing the video, to systematically explicate their lived experience in terms of practical actions (Durand, 2000, p. 249):

which are actions rooted in physical changes in the environment; communication, which are directed toward changes in the mental state of the persons interacting; interpretations, which are internalized actions or operations that may produce thought chains or private speech; focusing, which involves perceptual or cognitive concentration on delineated entities; and feelings, which are emotional and affective manifestations that are more or less differentiated and more or less pleasant or discomforting.

An interview guide was developed for this investigation based on previous research (e.g., Gréhaigne et al., 1999; Gréhaigne, Godbout, \& Bouthier, 2001). The guide consisted of the following questions: (a) Can you describe what happened at this moment (the moment illustrated by the sequence)? (b) What 
information did you take into account? (c) What was the principle that you applied? (In the sense of "action rule", i.e., the conditions to be respected and the elements that need to be considered to produce efficient action [Gréhaigne, Billard, Guillon \& Roche, 1988]. (d) What is the origin of this principle? In accordance with our theoretical and methodological framework (e.g., situated action, selfconfrontation interview), the interview guide was voluntarily limited and was used as a resource for the interview rather than to determine its course. The interview systematically began with the player being asked the first question (a). Throughout the interview, the player was asked a series of follow-up questions, including the last three questions of the interview guide if needed $(b-d)$. The goal of this interview was to obtain verbalizations with regard to a singular experience rather than interpretation, generalization, or expression of a judgment with regard to a class of experiences (Vermersch, 1994). The interviewer tried as far as possible to formulate open-ended questions and direct the subject's attention to a relatively well defined and identifiable moment. All interviews were audiotaped and then transcribed verbatim in line-numbered format, in preparation for data analysis.

\section{Data Processing}

Data processing was consistent with the qualitative nature of the data. Self-confrontation interviews were processed according to Huberman and Miles's (1991) double-level coding process. This inductive content analysis process consists of synthesizing verbalizations expressed by individuals into meaningful themes that link together similar ideas. Each interview was read carefully, and salient themes were transferred to an encoding form that included three columns: (a) lines numbers; (b) codes, which formed the first level of analysis; and (c) metacodes, which formed the second level of analysis. Participants' most representative verbalizations were underlined on the transcripts for further quotation. Two researchers independently classified a part of the raw data into the higher-order themes (1 interview, 98 codes), resulting in an interanalyst reliability coefficient of $88 \%$. The main investigator twice carried out the thematic analysis of another part of the raw data (1 interview, 326 codes), resulting in an intra-analyst coefficient of $93 \%$.

\section{Trustworthiness}

We used three methods to strengthen the trustworthiness of the data and our interpretations: (a) data triangulation, (b) multiple researchers, and (c) source checking. According to Griffin and Templin (1989), the first method consists of using different means to collect data and comparing them. Players' verbalizations were compared with the video and with the coach's instructions when provided.

Secondly, the main investigator regularly met, at various stages of the investigation, with the other researchers involved in the current study, to "explore biases, clarify interpretations and decisions made, and make explicit aspects that might otherwise remain only implicit within the inquirer's mind" (Jackson, 1995, p. 142). This precaution was particularly useful for identifying the moments when the interviewed subject ceased referring to the lived experience itself and began to intellectually construct extrapolations, commentaries, and/or fantasies regarding 
what her experience was or could be. During the meetings between coresearchers, a particular focus was set on linguistic indicators (e.g., rhythm of speech, forms of narrative) that characterize what Vermersch (1994) called the "speech position", that is, the relation between what is said and the experiential reference. On this basis, an agreement was reached on the kind of verbalizations that were not worth considering. These were excluded from the data analysis process. Here are two examples of such biased verbalizations: "Usually, when we apply this strategy, it doesn't work as it should" (Lauren); "Maybe we could have done a second wave but I don't think it was the best solution" (Lucy).

The third method relies on the participants' feedback about the results of the investigation (Locke, 1989). We applied source checking in the form of a collective meeting at the end of the data collection with all six elite players. All the participants agreed on the accuracy of the collected data.

\section{Results and Discussion}

The purpose of this study was (a) to investigate elements involved in successful decision making in team handball and (b) to provide teachers with useful teaching recommendations. In this section, we simultaneously present, interpret, and discuss the collected data. Then we discuss our findings more deeply, deduce their practical implications, and formulate teaching recommendations in the next section.

Table 2 presents the elements involved in decision making in offensive situations, whereas Table 3 presents the elements involved in decision making in defensive situations. In the tables, the frequency counts in parentheses reflect the numbers of raw data classified into the higher order themes, independently of the numbers of subjects and the numbers of video sequences. Hence, their interpretation has to be made with caution and in a qualitative rather than quantitative way.

Four main elements (metacodes) were identified in the decision-making process of elite team handball players, with slight differences between offensive and defensive situations: (a) perception, (b) knowledge, (c) expectations, and (d) context. They result from the categorization of 23 lower order elements (codes) that we illustrate and discuss below.

\section{Perception}

In this study, perception is more than the athletes' commonly considered use of sight (e.g., McMorris \& Graydon, 1997). Our findings show that, when making a decision, the elite players processed relevant cues they were not only visual but also auditory, tactile, and proprioceptive. Moreover, players frequently evoked different kinds of cues for a single action (e.g., visual and auditory cues). This supports Schmidt's (1989) assertion that several components of a stimulus are put together to select the most appropriate response possible.

Visual Cues. The key visual cues included information from the (a) opponents, (b) teammates, (c) ball, and (d) referees. The way elite players described visual information they were taking into account when making their decisions matches Mouchet's (2005) description of a passage from a distributed attention mode (par- 


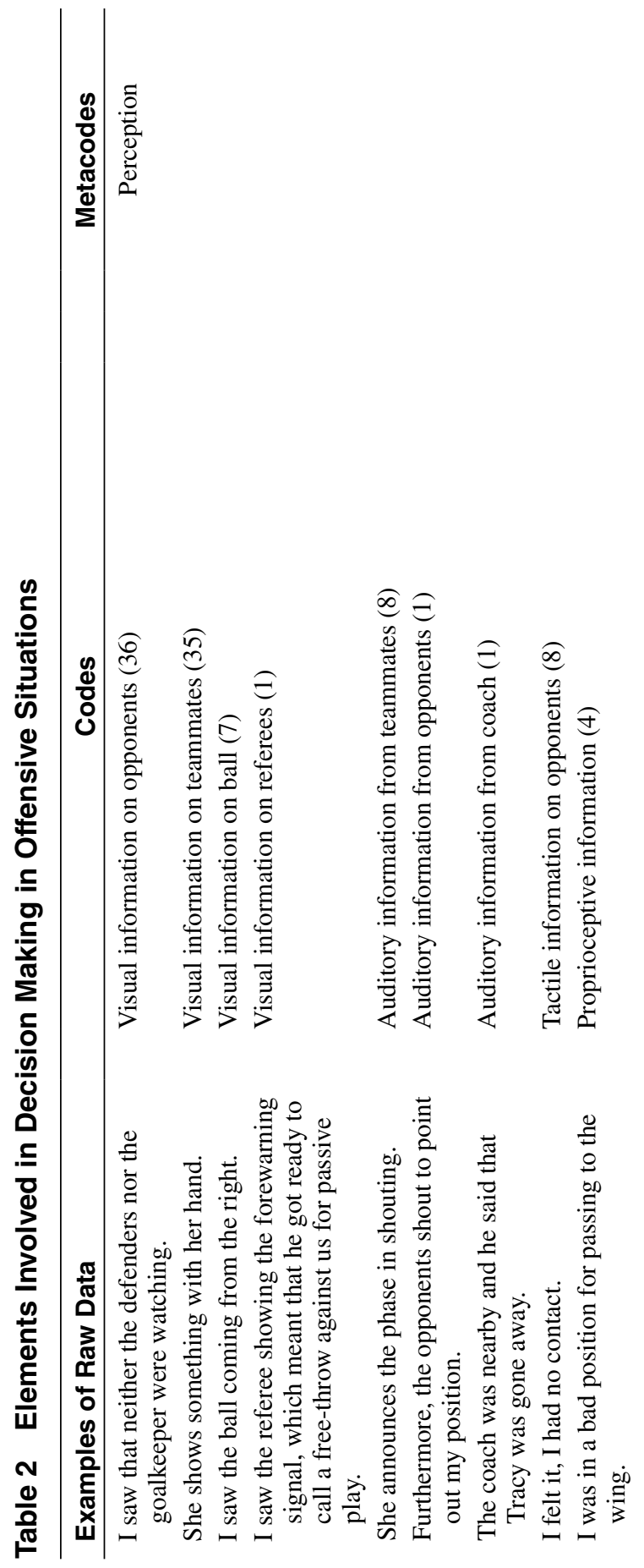




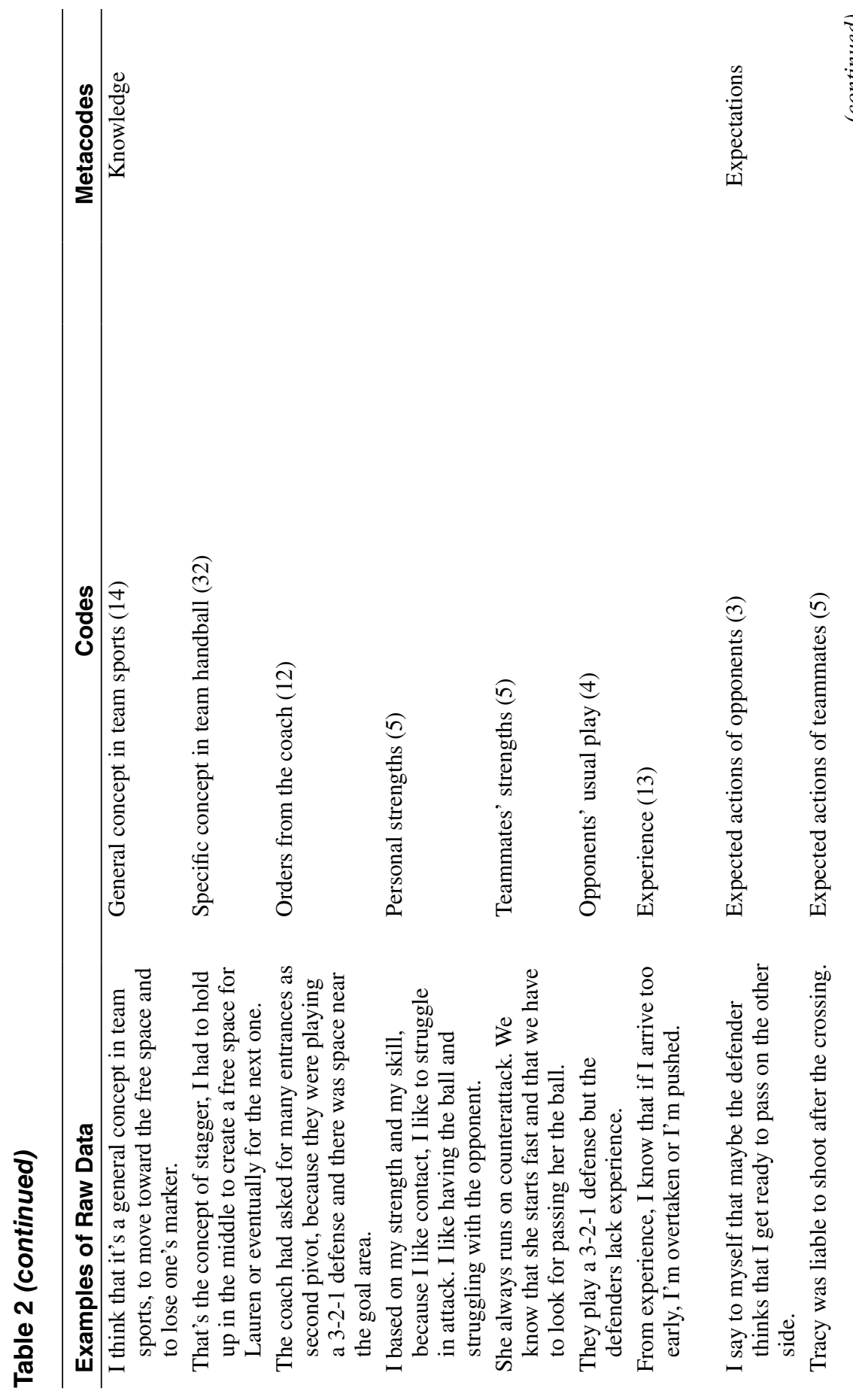




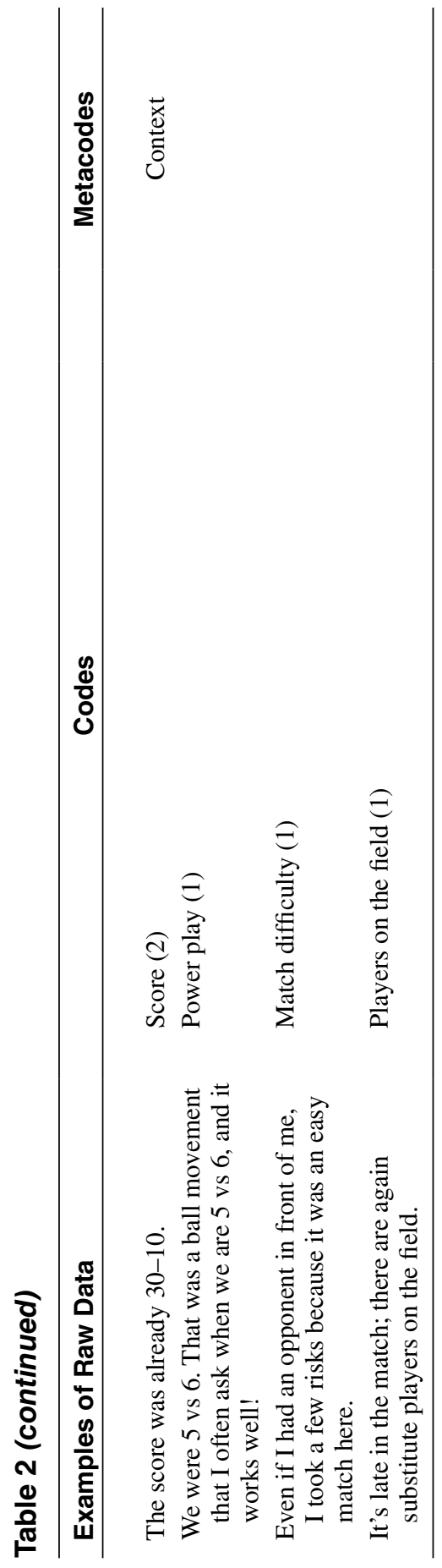




\section{Table 3 Elements Involved in Decision Making in Defensive Situations}

\begin{tabular}{|c|c|c|}
\hline Examples of Raw Data & Codes & Metacodes \\
\hline $\begin{array}{l}\text { I saw that the back had } \\
\text { changed of position. }\end{array}$ & Visual information on opponents (22) & Perception \\
\hline $\begin{array}{l}\text { I saw that the No. } 2 \text { was } \\
\text { gone forward. }\end{array}$ & Visual information on teammates (2) & \\
\hline $\begin{array}{l}\text { The right back was moving } \\
\text { away and she had the ball. }\end{array}$ & Visual information on ball (2) & \\
\hline $\begin{array}{l}\text { Mary informed me that the } \\
\text { pivot was between us. }\end{array}$ & $\begin{array}{l}\text { Auditory information from teammates } \\
\text { (5) }\end{array}$ & \\
\hline $\begin{array}{l}\text { I touched her, she was } \\
\text { beside me. }\end{array}$ & Tactile information on opponents (10) & \\
\hline $\begin{array}{l}\text { That's the way it is. Each } \\
\text { one has to mark an } \\
\text { opponent. }\end{array}$ & General concept in team sports (2) & Knowledge \\
\hline $\begin{array}{l}\text { I play libero; thus I have to } \\
\text { mark the pivot while Jane } \\
\text { has to mark the back. }\end{array}$ & Specific concept in team handball (14) & \\
\hline $\begin{array}{l}\text { The coach had asked to } \\
\text { play a 3-2-1 defense. }\end{array}$ & Orders from the coach (7) & \\
\hline $\begin{array}{l}\text { If I had gone onto her, she } \\
\text { would have cut around. I } \\
\text { prefer to save than to be } \\
\text { cut around. }\end{array}$ & Personal strengths (2) & \\
\hline $\begin{array}{l}\text { Sue is behind me. I know } \\
\text { that she's there because } \\
\text { Sue doesn't fall back fast. } \\
\text { She's a bit slow. }\end{array}$ & Teammates' weaknesses (1) & \\
\hline $\begin{array}{l}\text { I knew that they would } \\
\text { counterattack, because } \\
\text { they always do so. }\end{array}$ & Opponents' usual play (1) & \\
\hline $\begin{array}{l}\text { I was better positioned to } \\
\text { mark this player. . . I } \\
\text { have learned it like that. } \\
\text { I know that it's the way } \\
\text { it is. }\end{array}$ & Experience (3) & \\
\hline $\begin{array}{l}\text { I said to myself that if I } \\
\text { went too high and vacated } \\
\text { space for the pivot, the } \\
\text { wing would pass her the } \\
\text { ball. }\end{array}$ & Expected actions of opponents (4) & Expectations \\
\hline
\end{tabular}


tial collective plan) to a focal mode (e.g., gesture to be made, defender close to fix) and reciprocally. For example, when describing a defensive situation, Linda said:

I was looking at the ball carrier and the ball. I saw the ball leaving, thus I saw that she passed to the wing. Then, I saw the ball going past me with a bounce.

... When I saw the wing, I saw that she had quite a lot of space.

Such perceptual and cognitive skills figure among the conditions for a successful dialectic between strategy and tactics (Mouchet, 2005; Mouchet \& Bouthier, 2006). Expertise in sports has proved to result in players' more economical visual search activity (Ripoll et al., 1995; Williams, 2000) and players' ability to extract more meaningful information from their environment (Williams, 2000; Williams, Ward, Knowles, \& Smeeton, 2002).

Auditory Cues. Teammates and, to some extent, the opponents and the coach were main sources of auditory information in making game decisions. Auditory information from teammates is so expected that the absence of such information may itself constitute a factor helping them to make successful decisions. Commenting on a successful defensive action, Sue said, "Mary didn't shout to me, 'Mark the pivot!' So, I knew that I didn't have to pay attention to the pivot and that I could go onto the back."

Tactile Cues. Owing to the specificity of handball rules, contact with the opponents represents an important source of information that plays a noticeable role in the analysis of the evolution of the situation by elite team handball players. In the absence of such tactile information, the players knew that they were free of their markers, as illustrated in the following quotation relative to an attack: "I feel that she is no longer in contact with me" (Helen).

Proprioceptive Cues. Perception of one's own body position was used by the players in combination with one or more of the previous cues. Such proprioceptive information was only verbalized for offensive situations (Table 2) and contributed to reinforce decisions based on more significant elements.

\section{Knowledge}

Knowledge has most often been addressed in experimental or empirical studies as the outcome of teaching rather than as a resource for action (e.g., in previously mentioned studies on the technical/tactical debate). Our findings show that when making a decision, elite team handball players drew in part on relatively general knowledge about team sports and team handball, including orders from the coach. They also summoned up more singular knowledge such as knowledge about oneself, teammates and opponents, and experience.

General Concept in Team Sports. Owing to common characteristics between invasion games, players referred to concepts and principles that apply to most of them. Such knowledge (e.g., moving to open space, defending an area, marking an opponent) can be found in books devoted to team sports and games (e.g., Gréhaigne et al., 2005). 
Specific Concept in Team Handball. Players also refer to concepts and principles that apply specifically to team handball. Such knowledge can be found in sport-specific books and athletes have been acquiring this specific knowledge throughout their playing careers, ranging from 8 to 19 years. For example, when answering the question, "What was the origin of this principle?" Lauren said:

You know, fortunately I have had the opportunity to see the best players in the world. You know, as I have participated in many tournaments and championships, I have observed and I have learned by myself.

Orders From the Coach. Finally, players referred to concepts and principles that they had exclusively acquired under the influence of their coach. Such findings are not surprising given the years the studied players had spent with their coach, ranging from 3 to 8 years. For example, commenting on her role in the 3-2-1 defense, Mary said, "I am in the 3 there at the end and that's the coach who has taught it like that. If the opponent goes toward the second defender, I have to mark the pivot."

Personal Strengths. Players seemed to have acquired consciousness of their own resources and draw on such knowledge when making decisions in game. The resulting representations, which may be erroneous, are assumed to account for a larger part of players' decision-making process when they are in initiative situations (Temprado, 1991). However, regarding the quantitative importance of such representations, our methodology did not allow us to discriminate between attacks (which may be seen as initiative situations) and defensive actions (which may be considered as reactive situations). On the other hand, the role played by self-representation in game decisions is challenging for teachers and coaches anxious to improve players' decision-making performance, especially because it is related to the dialectic between strategy and tactics, as illustrated in the following quotation:

That's something that I like a lot, but that I seldom do here because the coach stops it. Here, in attack, we always have to ask something. The coach does not let us play as we want. But that's something that I have done frequently in Romania and I have scored many times in this way. (Lauren)

Teammates' Strengths/Weaknesses. Players' retrospective verbalizations regarding their teammates' characteristics reflect collective aspects of decision making in team sports. All the studied players had been playing together for at least 3 years. Hence, they had benefited from numerous opportunities to develop conscious interrelations between each other as team members.

Opponents' Usual Play. Given the relative stability of the elite female team handball circle, the studied players had been acquiring knowledge about the tactical systems commonly used by most of the opponents and their individual characteristics. For example, commenting on a successful attack, Lauren said, "If I had come slowly, I am sure that Melanie (given name of the opponent), with her experience, would have caught me." Such knowledge construction occurs from match 
to match, but may also occur throughout a single confrontation, as shown by Sève et al.'s (2003) observations that the commitment of elite players throughout a table tennis match wavers between inquiry phases, during which they construct knowledge, and executory phases, during which they apply new knowledge in resolving similar problems. Players' verbalizations suggested that, in team sports, the direct opponent and the goalkeeper represent the main source of learning, as illustrated by the following: "She is not a good goalkeeper. She anticipates too much. She moves long before the shot" (Linda).

Experience. Finally, players' retrospective verbalizations reflected some kind of meta-knowledge resulting from personal experience (e.g., when to apply previously mentioned knowledge). For example, commenting a successful attack, Lucy said, "It is also my personal experience; I have looked and I have decided if I could go or not."

\section{Expectations}

Owing to opponents' pressure, players might be forced to produce an adequate response in the shortest possible time. In these cases, they based their (re)actions on hypothetical actions undertaken by their opponents and their teammates. In other words, players made decisions in part on what they thought opponents and teammates were going to do.

Expected Actions of Opponents. The ability to anticipate an opponent's intentions based on postural cues provides a crucial performance advantage (Williams \& Grant, 1999; Williams et al., 2002). This ability was illustrated in Sue's verbalizations regarding a successful defensive action: "I felt that she was threatening because she was moving towards the goal; she was intending to shoot." Such perceptual and cognitive skills are even more crucial for handball goalkeepers (we had none among our participants), who have been shown to prepare their parry before the opponent's shot (Debanne, 2003).

Expected Actions of Teammates. Similarly to knowledge about teammates' strengths and/or weaknesses, anticipation of what their teammates might do reflected collective aspects of decision making in team sports gained from playing together across time. Expectations about the teammates' actions depend upon these teammates' characteristics and preferences, but also upon their status within the team (Gréhaigne et al., 2005).

\section{Context}

This category contains elements that were verbalized by elite players for offensive situations only (Table 2), which means that (a) score, (b) power play (when the team has a temporary numerical advantage), (c) players on the field, and (d) match difficulty may actually influence players' decision making in offensive situations. The first three elements $(\mathrm{a}-\mathrm{c})$ were also shown to influence a coach's decisions during hockey matches (Trudel, Haughian, \& Gilbert, 1996). All these elements (a-d) deal with the problem of risk taking in team sports. When applying decision field theory to a dynamic situation in soccer, Raab and Johnson (2005) assumed players were thinking about the following possible dimensions: (a) the "scoring 
potential" (i.e., assisting on a game-winning goal) or (b) the "safety potential" (i.e., losing the ball to the opponent late in the game). Our findings suggest that players" perception of the "momentum of the game" (score, power play, players on the field, match difficulty) may lead them to minimize the consequences of losing the ball and therefore adopt behaviors more risky than those planned into the framework of predetermined strategy. By extension, they underline the interest of the situated action paradigm for studying decision making in sport, insofar as this paradigm allows researchers to account for the complex relation of knowledge and action to the local circumstances (Suchman, 1987).

On the other hand, the absence of these contextual elements in players' verbalizations related to defensive situations does not necessary mean that such elements cannot influence defenders' decision making. This finding reflects the difficulty in provoking verbalizations without prompts and constitutes a limit to our approach. Our methodology allowed us to give credit to what players expressed, but we cannot consider that players verbalized in detail all the elements that entered their decision-making process.

\section{Implications for Teaching}

In this section, we make the connection between our findings, which actually show what handball players take into account when making game decisions, and teaching strategies to support pupils' learning in this area.

\section{Perception}

Researchers understand better and better the role of visual cues and visual search strategy in decision making in team sports (Mouchet, 2005; Ripoll et al., 1995; Williams, 2000; Williams et al., 2002). So, the question lies in how to create a teaching or training environment that can reinforce the acquisition of visual-related skills. Progress in this area can be facilitated through video simulation and instruction, such as important situational probabilities underlying performance, key information cues highlighted, and the biomechanics of shots (Williams et al., 2002). In physical education, "freeze-play" situations could be more easily used to this end.

Nonvisual cues (i.e., auditory, tactile, proprioceptive) have seldom been addressed in experimental or empirical studies and this constitutes a severe lack in the literature on decision making in sports, especially regarding didactic means to improve players' perceptual and cognitive skills. Besides using video simulation, which may deny players access to information that they would normally use in real-world settings (Abernethy, Thomas, \& Thomas, 1993), we propose manipulating various constraints during field teaching or training sessions (e.g., players are allowed to pass the ball only to partners who have called for it; pivot is allowed to receive the ball only if no opponent touches him). In their tactical games model, Griffin, Mitchell and Oslin (1997) have already suggested modifying playing rules to help teachers match tactical complexity to the developmental level of their students. Our proposal is heading in the same way, although aiming more specifically to help teachers improve their students' ability to extract nonvisual cues from their environment. 


\section{Knowledge}

Acquisition of general concepts in team sports can be facilitated through team handball courses or training sessions, of course, but also through practice of additional sport activities (Baker, Côté, \& Abernethy, 2003). By highlighting the "action rules" common to most invasion games, e.g., playing in movement, exploiting and creating available space, defending the target (Gréhaigne et al., 2005), physical education teachers would probably reinforce the transfer of skills across team sports.

Acquisition of more singular knowledge as knowledge about oneself, teammates, and opponents may be seen as an automatic result of playing together across time. However, in physical education, the "debate-of-idea" (Gréhaigne \& Godbout, 1998) — that is, situations in which, following game play action, learners exchange ideas, based on observation or on personal experience-may constitute an efficient tool to develop and improve such collective aspects of decision making. Improvement in this area could also be facilitated by applying some principles of the sport education model, such as lengthy physical education units and stable teams throughout the teaching cycle (Dyson, Griffin, \& Hastie, 2004; Siedentop, 1996). Finally, we suggest providing nonplaying pupils with scouting sheets to use when watching other teams they will play, to help determine strategy.

\section{Expectations}

Video-based simulation proved to be effective in improving players' anticipation of their opponents' actions (for a review, see Williams \& Grant, 1999). However, field-based training sessions involving (a) focus on improving visual attention and ball tracking and (b) key cues highlighted appear more suitable for physical education.

Predetermined strategy plays a notable role in the coordination between all team members (Gréhaigne et al., 1999). Likewise, the debate-of-idea (Gréhaigne $\&$ Godbout, 1998) may help pupils to develop and improve their reading of the collective game.

\section{Context}

Developing players' ability to adapt their actions to the requirements of the immediate circumstances is particularly challenging for teachers. To this end, it seems again to us that applying some principles of (a) the sport education model, such as teaching units defined by formal competition, which is interspersed with practice sessions (Dyson et al., 2004; Siedentop, 1996) and (b) the tactical games model, such as lesson sequences including games, question-answer segment, and situated practice (Griffin et al., 1997), would constitute an adequate response. Players have to be regularly confronted with real game situations before being able to develop efficient strategies regarding risk taking. Examples of teaching strategies and/or didactic contents are synthesized on Table 4. 


\section{Table 4 Examples of How Acquisition of Certain Team Sports Skills Can Be Facilitated During Teaching Sessions}

Skills to Be Acquired

Extraction of meaningful information from the environment

\section{Examples of Teaching Methodologies} and/or Didactic Contents

"Freeze-play" situations with instruction (e.g., important situational probabilities, key information cues highlighted, biomechanics of shots)

Manipulation of various constraints during field teaching (e.g., players are allowed to pass the ball only to partners who have called for it; pivot is allowed to receive the ball only if no opponent touches him)

\begin{tabular}{ll}
\hline $\begin{array}{l}\text { Knowledge about general concepts in team } \\
\text { sports and specific concepts in team handball }\end{array}$ & $\begin{array}{l}\text { Specific practice } \\
\text { Additional activities with instruction (e.g., } \\
\text { common "action" rules highlighted) }\end{array}$ \\
\hline $\begin{array}{l}\text { Knowledge about teammates' strengths/ } \\
\text { weaknesses }\end{array}$ & $\begin{array}{l}\text { Debate-of-idea } \\
\text { Unchanging teams throughout the teaching cycle }\end{array}$ \\
\hline Knowledge about opponents' usual play & $\begin{array}{l}\text { Unchanging teams throughout the teaching cycle } \\
\text { Nonplaying pupils provided with scouting sheets } \\
\text { for watching the other teams }\end{array}$ \\
\hline Anticipation of opponents' intention & $\begin{array}{c}\text { Field teaching involving focus on attention and } \\
\text { ball tracking, and key cues highlighted }\end{array}$ \\
Anticipation of teammates' intentions & Debate-of-idea \\
\hline $\begin{array}{c}\text { Adaptation of one's actions to the requirements } \\
\text { of the immediate circumstances }\end{array}$ & $\begin{array}{c}\text { Teaching unit defined by formal competition, } \\
\text { which is interspersed with practice sessions }\end{array}$ \\
\hline
\end{tabular}

\section{Conclusions}

This exploratory study brought us to a better understanding of the elements actually involved in decision making in team handball. Our findings show that not only visual but also auditory, tactile, and proprioceptive information may play a part in the decision-making process in game situations. To link the perceived dynamic configurations of play and the right decision(s) to be made, players may draw on knowledge from the more general (e.g., general concepts in team sports) to the more singular (e.g., teammates' strengths/weaknesses, opponents' usual play), whose acquisition relies on the instructors (e.g., orders from the coach) and on the competitive environment. Anticipation of opponents and teammates' intentions may also play a part-especially when opponents' pressure is high-in the decision-making process. Finally, contextual elements dealing with risk taking have been shown to influence players' decision making in only offensive situations. This does not necessarily mean that it is not the case in defensive situations. 
According to the situated action paradigm and its related methods, these findings cannot be generalized to other populations and contexts-to schools all the more so-in the form of a general model of decision making in game play. Furthermore, our findings may be incomplete owing to the complexity of the decision-making process and the difficulty in gaining access to players' subjective experience. On the other hand, they reflect the skills to be acquired for becoming a good team handball player. Therefore, they constitute a reliable source of inspiration for developing teaching strategies and didactic contents. Despite the limitations, situated analysis of decision making in team sports situations should be extended to provide preservice and in-service teachers and coaches with a theoretical basis aimed at improving their teaching and, as a result, players' learning and pleasure.

\section{Acknowledgments}

The authors would like to thank Bryan McCullick and Mary O'Sullivan for their careful proofreading of earlier versions of this paper. Thanks also to the reviewers for their helpful comments on this article.

\section{References}

Abernethy, B., Thomas, K.T., \& Thomas, J.T. (1993). Strategies for improving understanding of motor expertise (or mistakes we have made and things we have learned!). In J.L. Starkes \& F. Allard (Eds.), Cognitive issues in motor expertise (pp. 317-356). Amsterdam, The Netherlands: Elsevier.

Allison, S., \& Thorpe, R. (1997). A comparison of the effectiveness of two approaches to teaching games within physical education. A skill approach versus a game for understanding approach. British Journal of Physical Education, 28(3), 17-21.

Baker, J., Côté, J., \& Abernethy, B. (2003). Sport-specific practice and the development of expert decision-making in team ball sports. Journal of Applied Sport Psychology, $15,12-25$.

Bunker, D., \& Thorpe, R. (1982). A model for the teaching of games in secondary schools. Bulletin of Physical Education, 18(1), 5-8.

Busemeyer, J.R., \& Townsend, J.T. (1993). Decision field theory: A dynamic-cognitive approach to decision making in an uncertain environment. Psychological Review, 100, 432-459.

Clancey, W.J. (1993). Situated action: A neuropsychological interpretation (Response to Vera and Simon). Cognitive Science, 17, 87-107.

Debanne, T. (2003). Activité perceptive et décisionnelle du gardien de but de handball lors de la parade: les savoirs d'experts [Perceptive and decisional activity of goalkeeper during parry: experts skills]. STAPS, 62, 43-58.

Durand, M. (2000). Teaching action in physical education: A cognitive anthropology approach. In M. Piéron \& M. Ángel González Valeiro (Eds.), Ten years of "José María Cagigal" scholar lectures. Congresos de la Association Internationale des Ecoles Supérieures d'Education Physique (AIESEP) 1990-1999 (pp. 243-264). La Coruña, Spain: Universidade da Coruña, Servicio de publicaciónes.

Dyson, B., Griffin, L., \& Hastie, P.A. (2004). Theoretical and pedagogical considerations for implementing sport education, tactical games, and cooperative learning instructional models. Quest, 56, 225-239.

Faingold, N. (2001). De moment en moment, le décryptage du sens [From moment to moment, the deciphering of the meaning]. Expliciter, 42, 40-48. 
Gréhaigne, J-F., Billard, M., Guillon, R., \& Roche, J. (1988). Vers une autre conception de l'enseignement des sports collectives. In G. Bui-Xuan (Ed.), Méthodologie et didactique de l'éducation physique et sportive (pp. 490-505). Clermont-Ferrand, France: AFRAPS.

Gréhaigne, J-F., \& Godbout, P. (1998). Formative assessment in team sports with a tactical approach. Journal of Physical Education, Recreation, and Dance, 69(1), 46-51.

Gréhaigne, J-F., Godbout, P., \& Bouthier, D. (1999). The foundations of tactics and strategy in team sports. Journal of Teaching in Physical Education, 18, 159-174.

Gréhaigne, J-F., Godbout, P., \& Bouthier, D. (2001). The teaching and learning of decision making in team sports. Quest, 53, 59-76.

Gréhaigne, J-F., Richard, J-F., \& Griffin, L.L. (2005). Teaching and learning team sports and games. New York: RoutledgeFalmer.

Griffin, L.L., Mitchell, S., \& Oslin, J.L. (1997). Teaching sport concepts and skills: A tactical games approach. Champaign, IL: Human Kinetics.

Griffin, L.L., Oslin, J.L., \& Mitchell, S.A. (1995). An analysis of two instructional approaches to teaching net games [Abstract]. Research Quarterly for Exercise and Sport, 66(Suppl.), A-64.

Griffin, P., \& Templin, T.J. (1989). An overview of qualitative research. In P.W. Darst, D.B. Zakrajsek, \& V.H. Mancini (Eds.), Analyzing physical education and sport instruction (2nd ed., pp. 399-409). Champaign, IL: Human Kinetics.

Huberman, A.M., \& Miles, M.B. (1991). Analyse des données qualitatives. Recueil de nouvelles méthodes. Bruxelles, Belgium: De Boeck Université. ([Analysis of qualitative data. Body of new methods])

Jackson, S.A. (1995). Factors influencing the occurrence of flow state in elite athletes. Journal of Applied Sport Psychology, 7, 138-166 .

Lawton, J. (1989). Comparison of two teaching methods in games. Bulletin of Physical Education, 25, 35-38.

Lenzen, B., Brouwers, M., Dejardin, R., Lachi, M., \& Cloes, M. (2004). Comparative study of coach-athlete interactions in mixed Japanese martial art, female amateur track and field, and male professional basketball. International Journal of Sport Psychology, 35, 77-90.

Locke, L.F. (1989). Qualitative research as a form of scientific inquiry in sport and physical education. Research Quarterly for Exercise and Sport, 60, 1-20.

McMorris, T., \& Graydon, J. (1997). The contribution of the research literature to the understanding of decision making in team games. Journal of Human Movement Studies, 33, 69-90.

Mitchell, S.A., Griffin, L.L., \& Oslin, J.L. (1995). The effects of two instructional approaches on game performance. Pedagogy in Practice: Teaching and Coaching in Physical Education and Sports, 1, 36-48.

Mouchet, A. (2005). Subjectivity in the articulation between strategy and tactics in team sports: an example in rugby. Italian Journal of Sport Sciences, 12, 24-33.

Mouchet, A., \& Bouthier, D. (2006). Prendre en compte la subjectivité des joueurs de rugby pour optimiser l'intervention [Taking the subjectivity of rugby players into account for optimizing intervention]. STAPS, 72, 93-106.

Newell, A., \& Simon, H.A. (1972). Human problem solving. Englewood Cliffs, NJ: Prentice-Hall.

Raab, M., \& Johnson, J.G. (2004). Individual differences of action-orientation for risk taking in sport. Research Quarterly for Exercise and Sport, 75, 326-336.

Raab, M., \& Johnson, J.G. (2005). Novel analyses of decision-making process in real, complex environments. Retrieved on January 3, 2007, from http://www.uni-flensburg. de/ raab/research/TRANSCOOP2005_2008.pdf.

Ripoll, H., Kerlirzin, Y., Stein, J-F., \& Reine, B. (1995). Analysis of information processing, decision making, and visual strategies in complex problem solving sport situations. Human Movement Science, 14, 325-349 . 
Schmidt, R. (1989). Motor control and learning. Champaign, IL: Human Kinetics.

Sève, C., \& Ria, L. (2006). Formes de comptage des points et activité d'enquête de pongistes experts lors de matches [Scoring systems and expert table tennis players' inquiry activity during matches]. Science \& Motricité, 59, 69-82.

Sève, C., Saury, J., Ria, L., \& Durand, M. (2003). Structure of expert table tennis players' activity during competitive interaction. Research Quarterly for Exercise and Sport, 74, 71-83.

Siedentop, D. (1996). Physical education and education reform: The case. In S. Silverman \& C. Ennis (Eds.), Student learning in physical education: Applying research to enhance instruction (pp. 247-268). Champaign, IL: Human Kinetics.

Suchman, L. (1987). Plans and situated action. New York: Cambridge University Press.

Temprado, J.J. (1991). Les apprentissages décisionnels en EPS. In J.P. Famose, P. Fleurance, \& Y. Touchard (Eds.), L'apprentissage moteur. Rôle des représentations (pp. 131-155). Paris, France: Editions Revue E.P.S. ([Motor learning. The role of representations])

Theureau, J., \& Jeffroy, F. (1994). Ergonomie des situations informatisées. Toulouse, France: Octarès. ([Ergonomics of computerized situations])

Trudel, P., Haughian, L., \& Gilbert, W. (1996). L'utilisation de la technique du rappel stimulé pour mieux comprendre le processus d'intervention de l'entraîneur en sport [The use of stimulated recall for a better understanding of the coach's intervention process]. Revue des Sciences de l'Education, 22, 503-522.

Turner, A.P. (1996). Teaching for understanding: myth or reality? Journal of Physical Education, Recreation and Dance, 67, 46-48/55.

Turner, A.P., \& Martinek, T.J. (1992). A comparative analysis of two models for teaching games (technique approach and game-centered - tactical focus - approach). International Journal of Physical Education, 29, 15-31.

Vermersch, P. (1994). L'entretien d'explicitation. Paris, France: ESF. ([The explicitation interview])

Williams, A.M. (2000). Perceptual skill in soccer: Implications for talent identification and development. Journal of Sports Sciences, 18, 737-750 .

Williams, A.M., \& Grant, A. (1999). Training perceptual skill in sport. International Journal of Sport Psychology, 30, 194-220.

Williams, A.M., Ward, P., Knowles, J.M., \& Smeeton, N.J. (2002). Anticipation skill in a real-world task: measurement, training, and transfer in tennis. Journal of Experimental Psychology. Applied, 8, 259-270 . 